Saudi Journal of Medical and Pharmaceutical Sciences

Abbreviated Key Title: Saudi J Med Pharm Sci

ISSN 2413-4929 (Print) |ISSN 2413-4910 (Online)

Scholars Middle East Publishers, Dubai, United Arab Emirates

Journal homepage: https://saudijournals.com/sjmps

Original Research Article

\title{
Thyroid Status of Hypothyroid Infertile Women: A Study in a Tertiary Care Hospital of Bangladesh
}

\author{
Dr. Mst. Jesmin Akter*, Dr. Shahanaz Ahmed, Dr. Mohammad Kamal Hossain \\ Assistant Professor, Department of Gynecology \& Obstetrics, Cumilla Medical College \& Hospital, Cumilla, Bangladesh
}

DOI: $10.36348 /$ sjmps.2020.v06i11.006 $\quad$ | Received: 02.11.2020 | Accepted: 11.11 .2020 | Published: 20.11 .2020

*Corresponding author: Dr. Mst. Jesmin Akter

Abstract

Background: The prevalence of hypothyroidism in the reproductive age group is found up to 4\%. In many studies it had been claimed that, thyroid status is directly involved in women reproductive system. Although it differs in several places, communities, geographic areas and age-groups but it deserves more attention from the reproductive health physicians and even from world communities. Hypothyroidism can be easily detected by assessing serum thyroid stimulating hormone levels. Aim of the study: The aim of this study was to dig out the prevalence of hypothyroidism in infertile women and to assess their responses in treatment procedures. Methods and Materials: This was a descriptive observational study conducted in Cumilla Medical College and Hospital, Cumilla, Bangladesh, during the period from January 2019 to December 2019. In total 128 women attended the infertility Unit of the mentioned hospital for fertility treatment were finalized as the study population of this study. The regular investigations CBC, blood sugar of 2 hours GTT, TSH and Prolactin was done. Hypothyroidism was diagnosed when increased TSH and normal FT4. Levothyroxin were given hypothyroid patients depending upon TSH levels. Results: Total 128 participants $56.25 \%(\mathrm{n}=72)$ were with primary infertility and the rest $43.75 \%(\mathrm{n}=56)$ were with secondary infertility. In total $23 \%(\mathrm{n}=29)$ participants were hypothyroid whereas the rest $77 \%(n=99)$ participants were euthyroid and/or hyperthyroid. Among the hypothyroid (n=29) participants, 20 were subclinical hypothyroid which was $69 \%$ among hypothyroid participants and $15.63 \%$ among the total participants. In total 9 were frank hypothyroid which was 31\% among hypothyroid participants and $7.03 \%$ among the total participants. We found, the mean $( \pm \mathrm{SD}) \mathrm{S}$. TSH, S. FT4 and S. Prolactin were $7.23 \pm 2.45 \mathrm{mIU} / \mathrm{L}, 16.95 \pm 3.32$ $\mathrm{pmol} / \mathrm{l}$ and $51.83 \pm 10.70 \mathrm{ng} / \mathrm{ml}$ respectively. Conclusion: According to the findings of this study we can conclude that, careful diagnosis and treatment of hypothyroidism can ensure benefit a lot rather than going for unnecessary hormone assays and costly invasive procedures. The findings of this study may be helpful in the treatment arena of infertility of women and in further similar study.

Keywords: Infertility, thyroid disorder, hypothyroidism, TSH, PRL level.

Copyright (C) 2020 The Author(s): This is an open-access article distributed under the terms of the Creative Commons Attribution 4.0 International License (CC BY-NC 4.0) which permits unrestricted use, distribution, and reproduction in any medium for non-commercial use provided the original author and source are credited.

\section{INTRODUCTION}

The prevalence of hypothyroidism in the reproductive age group are found up to $4 \%$. In many studies it had been claimed that, thyroid status is directly involved in women reproductive system. Although it differs in several places, communities, geographic areas and age-groups but it deserves more attention from the reproductive health physicians and even from world communities. By assessing serum thyroid stimulating hormone(TSH) levels, hypothyroidism can be easily detected. We need a clear concept on this issue. Infertility may be a world health issue affecting approximately $8-10 \%$ of couple's worldwide [1]. WHO estimates the general prevalence of primary infertility in India to be $3.5-16.8 \%$ [2]. Both hyperthyroidism and hypothyroidism have deep effects on estrogen and androgen metabolism, menstrual function and fertility [3]. They may cause delayed onset of puberty, menstrual abnormalities, anovulatory cycles, miscarriages and infertility [4]. Hypothyroidism can be easily detected by assessing TSH levels. Slight increasing in TSH levels with normal T3 and T4 indicates subclinical hypothyroidism. Whereas high TSH levels amid low T3 and T4 levels indicate clinical hypothyroidism. Elevated thyrotropin- releasing hormone levels due to hypothyroidism are often associated with increased prolactin (PRL) levels and a delayed LH response to GnRH [5]. Thyroid dysfunctions is implicated in a broad spectrum of reproductive disorders, ranging from abnormal sexual development to menstrual irregularities and infertility [6]. It has been proved that for normal sexual function, 
thyroid secretion of T3, T4 need to be approximately normal. We had conducted this study to collect some specific information regarding hypothyroidism in infertile women and to assess their responses in treatment procedures.

\section{OBJECTIVES}

\section{General Objective}

- To find out the prevalence of hypothyroidism in infertile women and to assess their responses in treatment procedures.

\section{Specific Objective}

- To collect information regarding hormone level in hypothyroid participants.

\section{Methodology \& Materials}

This was a descriptive observational study conducted in Cumilla Medical College and Hospital, Cumilla, Bangladesh, during the period from January 2019 to December 2019. In total 128 women attended the infertility unit of the mentioned hospital for fertility treatment were finalized as the study population of this study. The study was approved by the ethical committee of the mentioned hospital. Proper written consents were taken from all the participants before starting data collection. The routine investigations such as CBC, blood sugar of 2 hours postprandial or GTT, TSH and Prolactin was done. Hypothyroidism was diagnosed when increased TSH and normal FT4. Hypothyroid patients got Levothyroxin depending upon TSH levels and continued until end of the study. Patients were followed up for 6 months albeit pregnancy was attained. TSH and PRL were measured by the electrochemiluminesence method as per the handbook for Elecsys, 2010 (Roche, USA). Normal TSH and PRL levels were respectively $0.27-5.0 \mathrm{U} / \mathrm{ml}$ and $1.9-25 \mathrm{ng} /$ $\mathrm{ml}$, as per kit supplier's instruction. Therefore, hypothyroidism was considered at TSH levels of $>5.0$ $\mu \mathrm{IU} / \mathrm{ml}$ and hyperprolactinemia at PRL levels of $>25$ $\mathrm{ng} / \mathrm{ml}$ when increased TSH and normal FT4. Hypothyroid patients got Levothyroxin depending upon TSH levels and continued until end of the study. Patients were followed up for 6 months albeit pregnancy was attained. Sign of ovulation was assessed by TVS, Day 21 serum progesterone. Chemical pregnancy when S. $\beta-H C G$ was $>15 \mathrm{mIU} / \mathrm{ml}$ and clinical pregnancy was confirmed by observing gestational sac with or without embryo with or without visible cardiac activity on USG. Statistical analysis was done by SPSS version 16 program.

\section{RESULTS}

The total study people were 128 in number. In this study we found the mean $( \pm \mathrm{SD})$ age of the participants was $25.51 \pm 4.75$ years. Besides this, the mean $( \pm$ SD) BMI was $25.21 \pm 3.18$ and the mean $( \pm$ SD) duration of suffering from infertility was $4.4 \pm 1.75$ years. Out of total 128 participants $56.25 \%(n=72)$ were with primary infertility and the rest $43.75 \% \quad(n=56)$ were with secondary infertility. In analyzing the major thyroid status of the participants we found, in total 23 $\%(\mathrm{n}=29)$ participants were hypothyroid whereas the rest $77 \%(n=99)$ participants were euthyroid and/or hyperthyroid. Then among the hypothyroid 29 participants 20 were subclinical hypothyroid which was $69 \%$ among hypothyroid participants and $15.63 \%$ among the total participants. On the other hand, 9 were frank hypothyroid which was $31 \%$ among hypothyroid participants and $7.03 \%$ among the total participants. In analyzing the hormone levels of the hypothyroid subjects we found, the mean $( \pm \mathrm{SD}) \mathrm{S}$. TSH, S. FT4 and S. Prolactin were $7.23 \pm 2.45 \mathrm{mIU} / \mathrm{L}, 16.95 \pm 3.32 \mathrm{pmol} / \mathrm{l}$ and $51.83 \pm 10.70 \mathrm{ng} / \mathrm{ml}$ respectively. On the other hand, in analyzing the treatment responses among the hypothyroid subjects we observed regular menstruation, normal ovulation, clinical pregnancy and chemical pregnancy were achieved by $86.21 \%(\mathrm{n}=25)$, $79.31 \%(n=23), \quad 65.52 \%(n=19)$ and $48.28 \%(n=14)$ paticipants respectively.

Table-I: General characteristics of participant's $(\mathbf{n}=128)$

\begin{tabular}{|l|l|l|}
\hline Variables & Mean & $\mathbf{\pm S D}$ \\
\hline Age (Year) & 25.51 & \pm 4.75 \\
\hline BMI & 25.21 & \pm 3.18 \\
\hline Mean duration of infertility (Year) & 4.4 & \pm 1.75 \\
\hline
\end{tabular}

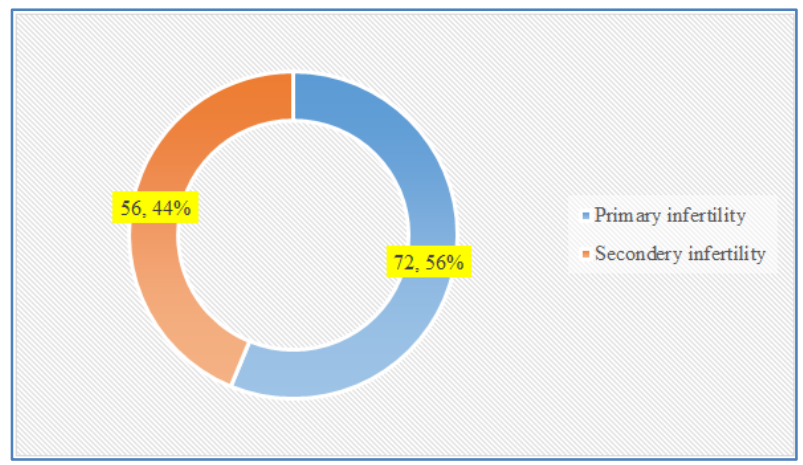

Fig-I: Types of infertility among participants $(n=128)$

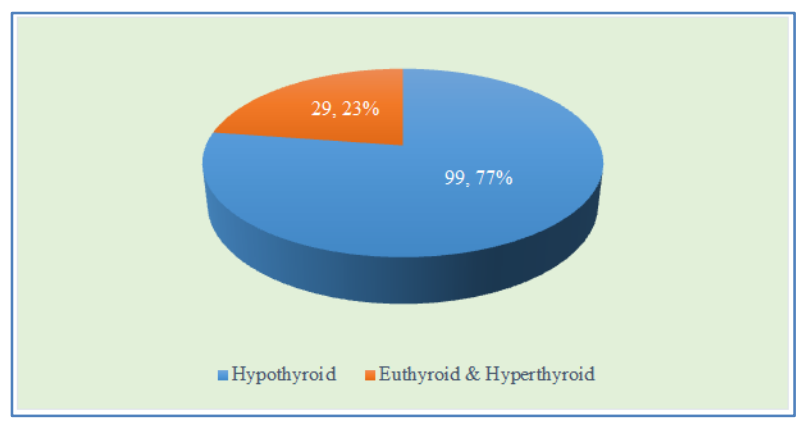

Fig-II: Major thyroid status of participants (n=128) 
Jesmin Akter et al., Saudi J Med Pharm Sci, Nov, 2020; 6(11): 704-707

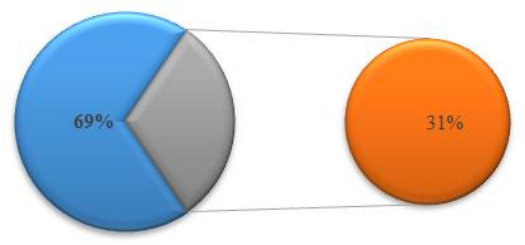

@ Subclinical hypothyroid घFrank hypothyroid

Fig-III: Thyroid status among hypothyroid participants $(\mathbf{n}=\mathbf{2 9})$

Table-II: Mean hormone level in hypothyroid participant's $(n=29)$

\begin{tabular}{|l|l|l|}
\hline Variables & Mean & \pm SD \\
\hline S. TSH $(\mathrm{mIU} / \mathrm{L})$ & 7.23 & \pm 2.45 \\
\hline S. FT4 $(\mathrm{pmol} / \mathrm{l})$ & 16.95 & \pm 3.32 \\
\hline S. Prolactin(ng/ml) & 51.83 & \pm 10.70 \\
\hline
\end{tabular}

Table-III: Treatment responses of hypothyroid Participant's (n=29)

\begin{tabular}{|l|l|l|}
\hline Outcome & n & \% \\
\hline Regular menstruation & 25 & 86.21 \\
\hline Ovulation & 23 & 79.31 \\
\hline Clinical pregnancy & 14 & 48.28 \\
\hline Chemical pregnancy & 19 & 65.52 \\
\hline
\end{tabular}

\section{DISCUSSION}

The aim of this study was to dig out the prevalence of hypothyroidism in infertile women and to assess their responses in treatment procedures. Hyperthyroidism (both clinical and subclinical) is thought to be found in approximately $2.3 \%$ of women presenting with sublertility[7], The link between hyperthyroidism and menstrual irregularity is well established-and is most frequently associated with hypomenorrhea and polymenorrhoea[8]. The probable mechanism for these menstrual disturbances is an increased sensitivity to gonadotrophin. Which releasing hormone resulting in a raised level of luteinizing hormone and sex hormone-binding globulin rise in total estrogens [9]. However, these thyroid-induced Thyroid dysfunction and reproductive health changes in the hypothalamo-pituitary-ovarian axis do not appear to be associated with anovulation and most women with hyperthyroidism remain ovulatory [10]. In our study in analyzing the major thyroid status of the participants we found, in total $23 \% \quad(n=29)$ participants were hypothyroid whereas the rest $77 \%(n=99)$ participants were euthyroid and/or hyperthyroid. Then among the hypothyroid $(n=29)$ participants 20 were subclinical hypothyroid which was $69 \%$ among hypothyroid participants and $15.63 \%$ among the total participants. On the other hand, 9 were frank hypothyroid which was $31 \%$ among hypothyroid participants and $7.03 \%$ among the total participants. Overt hypothyroidism is common which affecting $0.5 \%$ of women of reproductive age. Mild thyroid has a prevalence of around 2-4\%,13 and categorized TSH raising more than $4.5 \mathrm{mU} / 1$ in combination with normal T4(9-25pmol/1). In analyzing the hormone levels of the hypothyroid participants of our study we found that, mean S. TSH, S. FT4 and S. Prolactin were $7.23 \pm 2.45 \mathrm{mIU} / \mathrm{L}, 16.95 \pm 3.32 \mathrm{pmol} / 1$ and $51.83 \pm 10.70 \mathrm{ng} / \mathrm{ml}$ respectively which are also below the normal like previous study. Hypothyroidism may modify pituitary response by changing estrogen metabolism and circulating levels of sex hormonebinding globulin [11]. There is evidence of a dosedependent association, with women with higher serum TSH levels having greater menstrual disturbance and an ovulatory cycle [10]. Women presenting with subfertility also appear to have raised mean serum TSH levels [4] and increased rates of subclinical [12] and overt hypothyroidism compared with controls. Serum TSH raised levels may be associated with reduced rates of fertilization during assisted conception [13] and reduced pregnancy rates overall in women with a serum $\mathrm{TSH}$ of more than $2.5 \mathrm{mU} / 1$. Miscarriage is common which affecting one in five pregnancies approximately. In our study we found very limited cases of miscarriage but it was higher in many studies. Recurrent miscarriage, defined as three consecutive miscarriages, affects $1 \%$ of couples. Thyroid hormone plays an important role in embryonic development, particularly neurodevelopment until approximately 10 weeks of gestation the fetus is dependent on placental transfer of T4 from the mother. It is conventional that perhaps thyroid disease has long been associated with miscarriage [14]. Evidence for a direct association between hyperthyroidism (in the absence of AITD) and miscarriage is usually found limited. However, one study [10] has suggested a doubling of miscarriage rale in a group of hyperthyroid women without AITD, compared with euthyroid controls. The anticipated mechanism for this was a toxic effect of excess thyroid hormone on embryogenesis. In our study in analyzing the treatment responses among the hypothyroid patients we observed regular menstruation, normal ovulation, clinical pregnancy and chemical pregnancy were achieved by $86.21 \%(\mathrm{n}=25), \quad 79.31 \%(\mathrm{n}=23)$, $65.52 \%(\mathrm{n}=19)$ and $48.28 \%(\mathrm{n}=14)$ participants respectively. These findings were similar to many other studies. Graves' disease is the most common cause for hyperthyroidism in pregnancy, affecting up to $1 \%$ of pregnancies. Frequently the diagnosis will have already been made, but for those in whom the diagnosis of hyperthyroidism is made in pregnancy. It can be difficult to differentiate from gestational hyperthyroidism, which affects between $1 \%$ to $3 \%$ of all pregnancies and occurs stimulation of TSH receptors by b-hCG [15].

\section{Conclusion}

According to the findings of this study we can conclude that, careful diagnosis and treatment of hypothyroidism can ensure benefit a lot rather than going for unnecessary hormone assays and costly 
invasive procedures. The normal TSH levels are the pre-requisite for fertilization. The decision to thyroid replacement therapy in subclinical hypothyroidism at early stage is justified in infertile women.

\section{REFERENCES}

1. Inhorn, M. C. (2003). Global infertility and the globalization of new reproductive technologies: illustrations from Egypt. Social science \& medicine, 56(9), 1837-1851.

2. World Health Organization, \& World Health Organization. (2004). Infecundity, infertility, and childlessness in developing countries. DHS Comparative Reports, 9.

3. Talwar, P. P., Go, O. P., \& Murali, I. N. (1986). Prevalence of infertility in different population groups in India and its determinants. Statistics and demography.

4. Unisa, S. (1999). Childlessness in Andhra Pradesh, India: treatment-seeking and consequences. Reproductive health matters, 7(13), 54-64.

5. Raber, W., Nowotny, P., Vytiska- Binstorfer, E., \& Vierhapper, H. (2003). Thyroxine treatment modified in infertile women according to thyroxine- releasing hormone testing: 5 year follow- up of 283 women referred after exclusion of absolute causes of infertility. Human reproduction, 18(4), 707-714.

6. Trokoudes, K. M., Skordis, N., \& Picolos, M. K. (2006). Infertility and thyroid disorders. Current Opinion in Obstetrics and Gynecology, 18(4), 446451.

7. Poppe, K., Glinoer, D., Van Steirteghem, A., Tournaye, H., Devroey, P., Schiettecatte, J., \& Velkeniers, B. (2002). Thyroid dysfunction and autoimmunity in infertile women. Thyroid, 12(11), 997-1001.
8. Krassas, G. E., Pontikides, N., Kaltsas, T. H., Papadopoulou, P., \& Batrinos, M. (1994). Menstrual disturbances in thyrotoxicosis. Clinical Endocrinology, 40(5), 641-644.

9. Marques, P., Skorupskaite, K., George, J. T., \& Anderson, R. A. (2018). Physiology of GnRH and gonadotropin secretion. In Endotext [Internet]. MDText. Com, Inc.

10. Jefferys, A., Vanderpump, M., Yasmin, E. (2015). Thyroid dysfunction and reproductive health. The Obstetrician \& Gynaecologist, 17:39-45.

11. Saran, S., Gupta, B. S., Philip, R., Singh, K. S., Bende, S. A., Agroiya, P., \& Agrawal, P. (2016). Effect of hypothyroidism on female reproductive hormones. Indian journal of endocrinology and metabolism, 20(1), 108-113.

12. Maraka, S., Singh Ospina, N. M., Mastorakos, G. \& O'Keeffe, D. T. (2018). Subclinical Hypothyroidism in Women Planning Conception and During Pregnancy: Who Should Be Treated and How? Journal of the Endocrine Society, 2(6), 533-546.

13. Reinblatt, S., Herrero, B., Correa, J. A. ShalomPaz, E., Ata, B., Wiser, A., Morris, D. \& Holzer, H. (2013). Thyroid stimulating hormone levels rise after assisted reproductive technology. Journal of assisted reproduction and genetics, 30(10), 1347-1352.

14. Moog, N. K., Entringer, S., Heim, C., Wadhwa, P. D., Kathmann, N., \& Buss, C. (2017). Influence of maternal thyroid hormones during gestation on fetal brain development. Neuroscience, 342, 68-100. H

15. Kamath, B. R., Rao, K. J., \& Mayadunne, A. A. (2001). Thyrotoxicosis in pregnancy: A case report. Journal for scientific research. Medical sciences, 3(2), 113-115. 